\title{
Analysis of the possibility of applications for a two-phase reverse thermosyphon in passive heat transport systems
}

\author{
Michal Duda ${ }^{1, *}$, Jurij Dobrianski ${ }^{2}$, and Daniel Chludzinski ${ }^{1}$ \\ ${ }^{1}$ University of Warmia and Mazury in Olsztyn, Department of Electric and Power, Electronics and \\ Automation, 11 Oczapowskiego St., 10-736 Olsztyn, Poland \\ ${ }^{2}$ University of Warmia and Mazury in Olsztyn, Faculty of Geodesy, Geospatial and Civil \\ Engineering, 15 Prawochenskiego St., 10-720 Olsztyn, Poland
}

\begin{abstract}
Devices called reverse thermosyphon enable passive heat transfer when the heat source is above the place of its receipt. This is often the case in solar installations for the preparation of hot water. The article concerns the determination of the possibility of using a two-phase inverted thermosyphon with two working factors in a passive downwards heat transport installation. The analysis was carried out on the basis of previous experimental studies. The height of the tested installation in one case was $1.5 \mathrm{~m}$, in the second $18 \mathrm{~m}$, at a heat load of 300,600 and $900 \mathrm{~W}$. Water and pentane was used as a working fluid inside the loop. Initial conclusions from the analysis confirm the possibility of using reverse thermosyphon with two working factors in the construction of a passive heat transport system.
\end{abstract}

\section{Introduction}

For many years the passive heat transport systems were studied. Although heat transfer in a case when the heat source is placed below the heat sink is not a problem and is widely applied, the passive heat transfer downwards for a long distance is still problematic. Currently, there are many interesting solutions to this issue. The passive heat transport systems can be classified as a system with liquid heat carrier (one phase system) and system with vapor heat carrier (two phases system). Genealogy of passive two phases closed systems was described by Khandekar [2]. He proposed to divide these devices into three different groups: A - wick heat pipe, B - wickless heat pipe (thermosyphon) and group $\mathrm{C}$ - close loop pulsating heat pipe. Devices in each of group have the solutions which allow for downward heat transfer. Contrary to the device which realizes upward heat transfer, these devices need some kind of mechanism which allows for liquid upward movement from the cooled section to the heated section. The cold liquid upward movement may be realized by capillary forces, pumping by vapor bubbles, vapor pressure using or osmotic forces. The capillary soaking forces are used for liquid return in the wick heat pipes among which are anti-gravity heat pipes designed for downward heat transfer. The studies of the

* Corresponding author: michal.duda@uwm.edu.pl 
anti-gravity loop-shaped heat pipes were presented in [3-6]. Another group of devices is the closed loop pulsating heat pipe where vapor bubbles for liquid upward movement are used [7] and so-called reverse thermosyphon which uses saturated vapor pressure. An overview of technical solutions based on vapor pressure for liquid upward movement in reverse thermosyphons has been described by Filippeschi [8]. These types of devices were tested as well by Meng-Chang at al. [9] and Kadoguchi at al. [10]. In devices where saturated vapor pressure is used to the liquid lifting, a condition of the heat transfer strongly depends on the heat transport height and gets worse when the height increases. This problem is not so essential when heat transfer is realized horizontally [11] or a liquid heat carrier is used [12-14]. This paper presents the construction and principle of operation of a reverse thermosyphon with two working agents, where liquid transfers heat. Also, the measurements carried out in reverse thermosyphon were described and dependence between agent parameter modification, heat load and height of heat lifting was discussed.

\section{Description of the device and operation principle}

Fig. 1. presents the construction and operation principle of a reverse two-phase thermosyphon with two working agents. Device construction was described in detail in $[15,16]$. The device consists of hot vessel A, cold vessel B and heat exchanger situated in the cooling section. Vessels are located one above another and the heat exchanger is situated on the lower part of the circuit. Heat is applied to the vessel A which is the so-called hot working vessel. This vessel is connected to the heat exchanger by a descending pipe. The heat exchanger from another side is connected with the cold working vessel by an ascending pipe. The vessels are connected with one another by two pipes: a passage pipe and an intermediate pipe. To provide a right working agent direction flow, the check valves in device and control valve situated in hot vessel A on the inlet to passage pipe were used.

a)

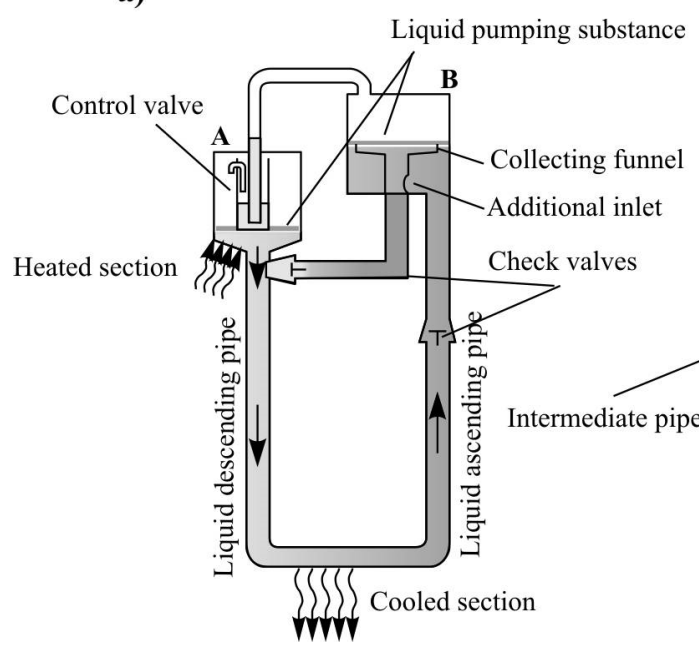

b)

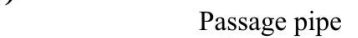


liquid level in vessel A. The pumping phase takes place in a situation when the control valve is closed. Heat applied to vessel A results in the liquid and vapor temperature increasing and thereby the pressure in hot branch increasing. As a result, a pressure difference in the circuit is observed. It determines the heated carrier flow from the heating section (vessel A) to the heat exchanger in the cooling section. A cold carrier from the heat exchanger flows to the cold vessel $\mathrm{B}$ where it is stored until the control valve changes position. When the control valve opens, liquid working agent returns to the heating section (vessel A) caused by gravitation force.

The device contains an additional low-boiling agent which is used as a pumping agent. A vapor of this agent causes the pumping of the liquid heated carrier. In the return phase, an overfill of vapor working agent flows to vessel B therefore vapors pressure in both vessels become equal. The working agent in vessel B condenses during pumping phase and heats the stored there cold carrier and device wall. The low-boiling agent floats on the surface of the heat carrier because its density is lower than the density of the heat carrier. In the inlet of vessel B a collecting funnel was situated, it allows condensate of the pumping agent return to the heating section. In Fig. 2 a working vessels view of the studied device is presented.

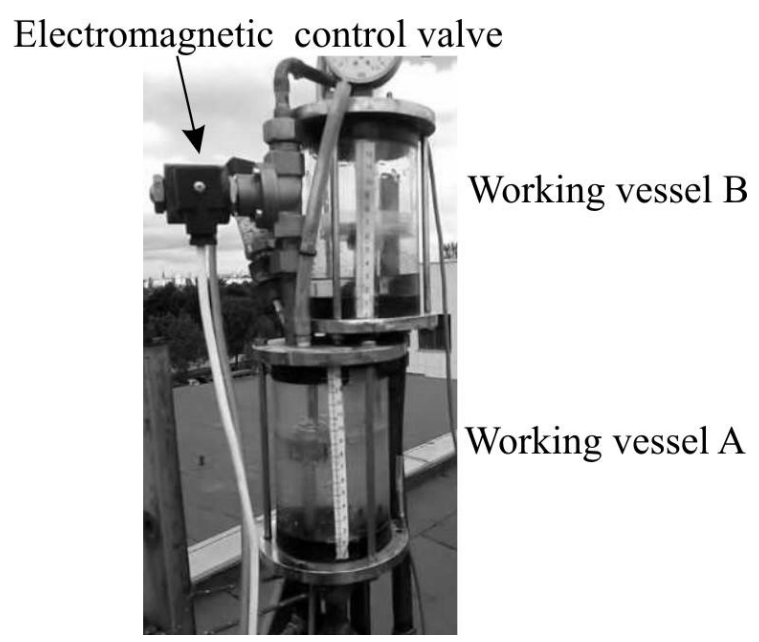

Fig. 2. The working vessels view of the studied device.

For control of the reverse thermosyphon operation, an electromagnetic valve was used. During experiments, the valve switched automatically in dependence on to the liquid level in vessel A. Water as the heat carrier and the pentane as pumping agents were used. Experiments were performed by heat load: $300,600,900 \mathrm{~W}$. The heat was transporting to a water reservoir with 30 liters volume located in the cooling section. The measurements were carried out when the temperature in the water reservoir fluctuated from 20 to 40 degrees Celsius. During the measurements, the following parameters were automatically registered: temperature, vapor pressure, heat carrier flow, heating power (heat load). In Fig. 3 the measurement points' localization are presented. 


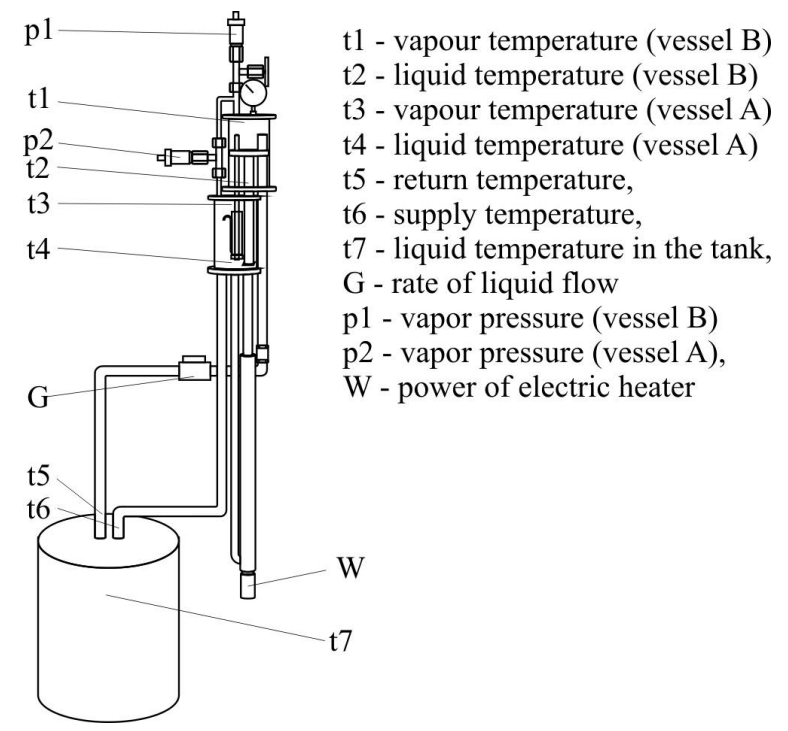

Fig. 3. Localization of measurement points.

\section{Results and discussion}

Diagrams in Fig. 4 present the temperature: T1, T2, T3, T4 and vapor pressure: p1, p2 in working vessels and liquid temperature $\mathrm{T} 7$ in the reservoir during first 10 minutes of the measurement with the heat load of $600 \mathrm{~W}$.
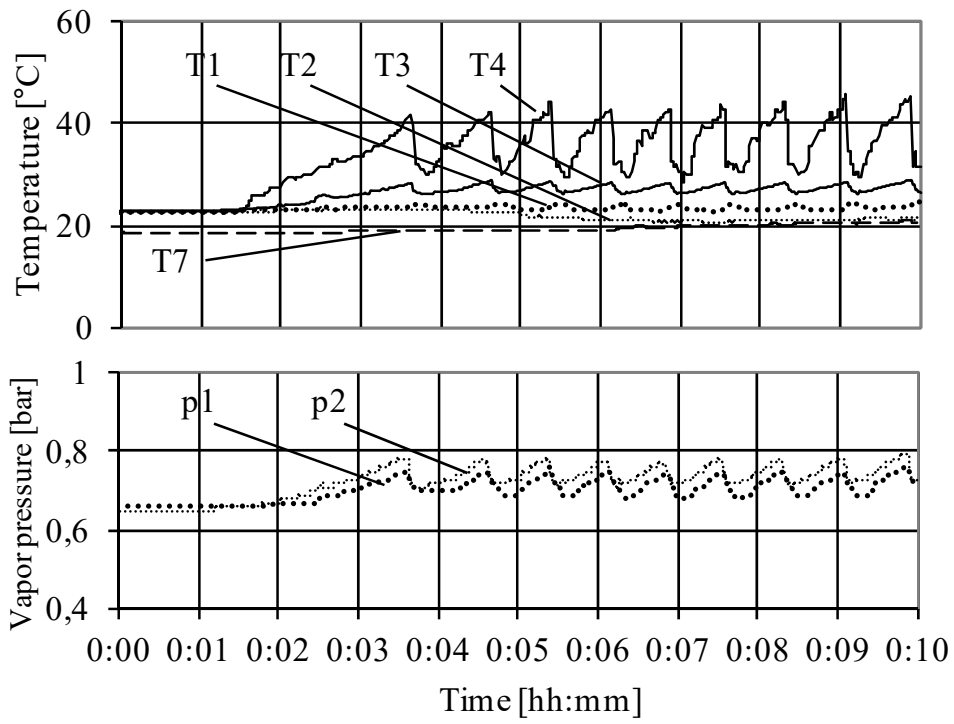

Fig. 4. Fundamental heat transport characteristics of reverse thermosyphon.

The repeated temperature and pressure variation expresses the work periods. A time when temperature and pressure increases are heated is during the carrier pumping phase. In this time the heat from the heated section to the cold section is transferring. The time when temperature and pressure in vessels decrease is a phase of liquid return (both of heat carrier and pumping agent condensate) from working vessel $\mathrm{B}$ to working vessel $\mathrm{A}$. 
In a short time after the start of the device operating, the temperature of the water reservoir in the cooling section and temperature of liquid in cold vessel level out. At the same time, a temperature difference between vapor and liquid in working vessel $\mathrm{A}$ and $\mathrm{B}$ remains constant, it indicates a lack of thermodynamic equilibrium of liquid and vapor. It should be noted, that the temperature difference between vapor and liquid is higher in vessel A.

The pressure vapor difference value depends on the liquid level difference in working vessels. Due to the liquid level difference in working vessels being variable at the time of the cycle, the pressure difference is variable as well. The lowest liquid level difference takes place at the start of the cycle while it is the highest at the end of pumping phase which precedes the liquid return phase. In Fig. 4 the change of the liquid level in working vessel A and associated liquid level difference in working vessels in a simple period was presented.
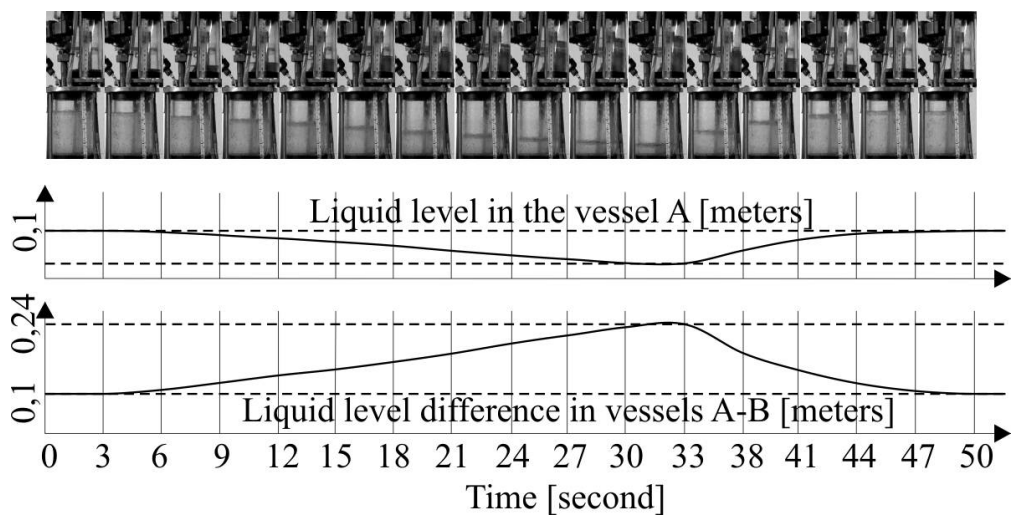

Fig. 5. Liquid level in work vessels in the work cycle.

The liquid lifting height is equal to the liquid difference in working vessels at the end of the pumping phase. The liquid lifting pressure may be calculated by $\rho g \Delta h$, where $\rho$ is the density of the liquid heat carrier and $g$ the gravitational acceleration. The calculated value of $\rho g \Delta h=2,35 \mathrm{kPa}$ is also indicated by the dashed line in Fig. 5. In any case, the vapor pressure difference in vessels at the end of pumping phase roughly corresponds to the liquid lifting pressure, irrespective of the heat load and heat transport height. It leads to the conclusion that the vapor pressure difference is determined by the liquid lifting height.

The lowest pressure difference was observed at the heat load of $300 \mathrm{~W}$ while the highest was recorded at $900 \mathrm{~W}$. In an additional test at the heat load of $600 \mathrm{~W}$ and heat transport height of $18 \mathrm{~m}$ an increase of pressure difference was not observed. It may prove that heat transport height has a weak influence on heat transport conditions in the reverse thermosyphon.

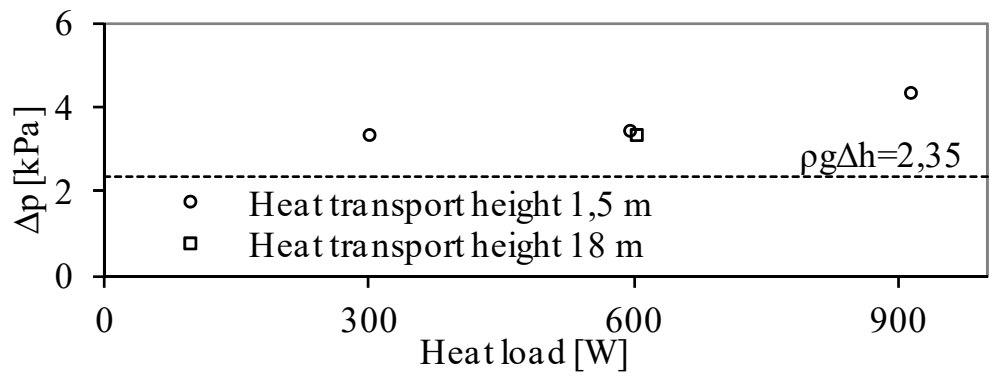

Fig. 6. Vapor pressure difference in working vessels at different heat load and heat transport height. 
In the reverse thermosyphon, a cycle length is according to the heat load. The higher heat load causes that the single cycle period decrease (Fig. 6). A relationship between cooling section temperature and cycle length is observed as well. According to the water temperature decrease in the cooling section the single cycle length increase is insignificant. The change in the length of the cycle time is related to the pumping phase time. With an increased heat load, the evaporation process takes place more intensively; it results in an increase in the heat carrier flow speed in the cooled section circuit.

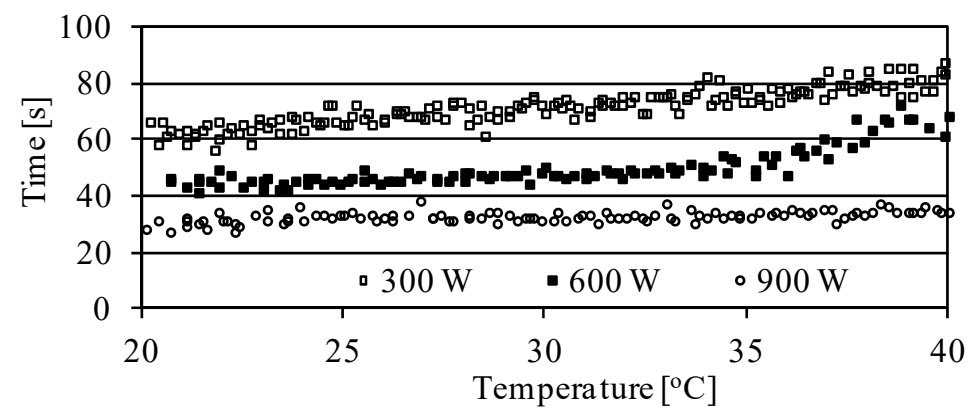

Fig. 7. Single-cycle length in dependence on heat load and liquid temperature in cooling section.

Fig. 7. presents the comparison of the efficiency of heat transport in dependence on heat load. The efficiency was calculated by the comparison of the heat amount stored in a water reservoir in the cooling section and the heat amount delivered to the heating section at the same time. The amount of the heat transported in each case was defined by liquid temperature increase in the water reservoir of the total volume of 30 liters. The efficiency of heat transfer in the circuit varies between $55 \%$ - at the $600 \mathrm{~W}$ heat load and $18 \mathrm{~m}$ of heat transport height and $70 \%$ at the $900 \mathrm{~W}$ and $1,5 \mathrm{~m}$ of heat transport height. Measurements were proceeded at the temperature of 20 degrees Celsius. It may be observed that a heat loss is independent of heat load. Higher heat load causes a lower loss in the circuit.

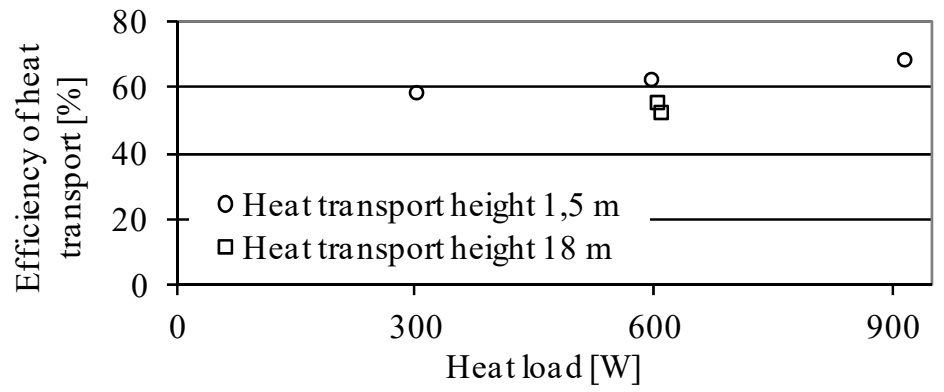

Fig. 8. The efficiency of heat transport in various heat load and heat transport height.

\section{Conclusions}

This paper presents the analysis of the possibility of using a two-phase reverse thermosyphon with two working agents and liquid heat carrier for passive heat transport downward. The device was tested in the heat load of 300,600 and $900 \mathrm{~W}$. The present studies can be concluded as follows:

(1) Application of the low-boiling agent (pentane) in reverse thermosyphon with water as the heat carrier allowed obtaining an atmospheric pressure in the circuit at the temperature of 36 Celsius. Obtained condition limits the possible leaks non-condensing gas to the circuit. 
(2) System operation details (temperature and pressure periodicity in working vessels) with two different working agents remains identical as for system with one working agent.

(3) The efficiency of heat transport in the studied system is comparable to similar systems with one working agent.

\section{References}

1. Y. Dobriansky, Energy Convers. Manage. 52, 414-425 (2011)

2. S. Khandekar, Thermo-hydrodynamics of closed loop pulsating heat pipes, (Institut für Kernenergetik und Energiesysteme der Universität Stuttgart 2004)

3. Y. Tang, R. Zhou, L. Lu, Z. Xie, Appl. Therm. Eng. 36, 78-86 (2012)

4. H. Li, X. Wangb, Z. Liu, Y. Tang, W. Yuan, R. Zhou, Y. Li, Exp. Therm. Fluid Sci., 68, 689-696 (2015)

5. H. Li, Y. Tang, W. Yuan, R. Zhou, Int. J. Heat Mass Transfer, 109, 824-834 (2017)

6. X. Ji, Y Wanga, J. Xu, Y. Huang, Appl. Therm. Eng. 117, 782-798 (2017)

7. W. Deng, Z. Xie, Y. Tang, R. Zhou, Exp. Therm. Fluid Sci. 41, 4-11 (2012)

8. S. Filippeschi, Int. J. Therm. Sci. 45, 124-137 (2006)

9. T. Meng-Chang, K. Shung-Wen, L. Heng-Yi, T. Wen-Fa, Journal of Applied Science and Engineering, 18(3), 259-264 (2015)

10. K. Kadoguchi, M. Yamazaki, Appl. Therm. Eng. 24, 2761-2775 (2004)

11. Y. Koito, Y. Ikemizu, T. Tomimura, M. Mochizuki, A vapor-pressure-driven heat pipe for sideward long-distance heat transport, (Frontiers in Heat Pipes (FHP), 1, 013005, 2010)

12. Y. Dobriansky, Y.G. Yohanis, 31(1), 3-32 (2010)

13. Y. Koito, M. S. Ahamed, S. Harada, H. Imura, Appl. Therm. Eng. 29, 259-264 (2009)

14. S. Ito, K. Tateishi, N. Miura, Studies of a Thermosyphon System with a Heat Source Near the Top and Heat Sink at the Bottom. (Goswami D.Y., Zhao Y. (eds) Proceedings of ISES World Congress 2007 (Vol. I - Vol. V). Springer, Berlin, Heidelberg, 2008)

15. M. Duda, J. Dobriansky, D. Chludziński, Scientific letters of Rzeszow University of Technology, RUTMech, XXXI, 86 (2/14), 183-190 (2014)

16. J. Dobrianski, D. Chludzinski, M. Duda, R. Wojcik, J. Piechocki, M. Samsel, Method and device for self-acting heat transfer in a direction reverse to natural convection, $(\mathrm{PL}$ Patent 217073, 2014) 